\title{
OPTIMIZATION OF THE COOLING OF A THERMOPLASTIC INJECTION MOLD
}

\author{
A. Chaabene, S. Chatti*, M. Ben Slama \\ Laboratory of Mechanical Engineering (LGM), National Engineering School of Monastir (ENIM), \\ University of Monastir, Rue Ibn El Jazzar, 5000 Monastir, Tunisia \\ *Corresponding author’s e-mail address: sami.chatti@udo.edu
}

\begin{abstract}
In injection molding processes for thermoplastic parts, the polymer solidification phase in the molding cavity has a strong influence on the quality of the shaped parts and also on the process cycle time. Reducing cycle time is one of the major concerns for plastic injection industries. As cooling phase presents the most critical phase to get quality and cycle time of the part, the application of additive manufacturing (AM) technologies has been overcoming the limitations of traditional cooling system design. $A M$ enables the construction of conformal cooling channels for higher cooling uniformity due to its almost unlimited freedom of design that can fulfil the desired functions in injection molding process equipment. The analysis of the heat transfer during the phase of cooling allows the investigation of the optimal positioning of the cold sources and their intensities. In this paper, a systematic approach is used to replace conventional channels in an injection molding tool with conformal cooling channels. A simulation is used to develop a numerical model that describes the heat transfer and predicts the cycle time of both the optimal and conventional designs. Finally, a numerical comparison is made between traditional and conformal cooling to demonstrate the beneficial effect on reducing the manufacturing cycle and enhancing part quality.
\end{abstract}

KEYWORDS: plastic injection, conformal cooling, Moldflow Insight, cooling time, warping.

\section{INTRODUCTION}

In the manufacture of mechanical parts, there are several shaping processes, including thermoplastic injection molding. Injection molding makes it possible to manufacture parts of complex geometry in large series, following a simple operating principle. Its success is dependent on the ability to produce 3D shapes more rapidly than other manufacturing techniques. The basic concept behind the molding process is whether a solid polymer is melted and injected into a cavity within a mold that will then be cooled, and the part is removed out from mold cavity when the process is completed. Accordingly, the injection molding is classified into five distinct stages: plasticization, injection, holding, cooling, and ejection. A new injection will be made when the tool is closed again. The cycle time must be assessed but also adapted to be the shortest possible to increase productivity and, as a result, to make the manufacturing methods more cost effective. The variable "time" is the critical link in any manufacturing process efficiency.

The injection molding process can be divided into five distinct steps: closing the mold, filling, packing and holding, cooling the part, and finally opening and ejecting the part. The cooling step takes the most time in this process, accounting for approximately $60 \%$ of the cycle duration (Fig. 1). The length of the cooling cycle directly affects the speed of the manufacturing of the plastic products. In order to control this variable, it is important to understand the phenomena of heat transfer in a mold [1].

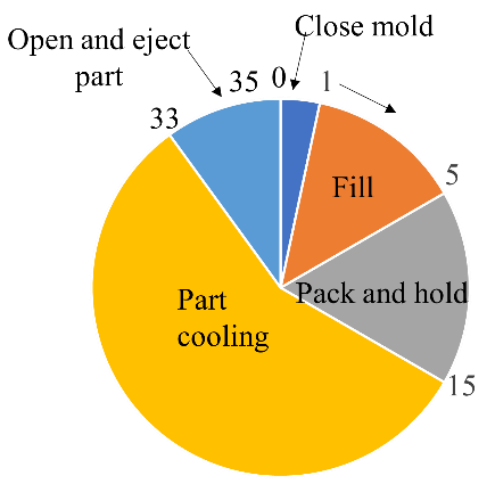

Fig. 1. Injection molding cycle time [2] 
The current work is concerned with the injection molding analysis and optimization, with a particular emphasis on the mold cavity. This study considers process parameters as well as mold design. The paper describes the creation of a smart plastic mold cavity with conformal cooling channels for the production of an automotive part with varying thickness.

\section{STATE OF THE ART}

\subsection{Summary of the Molding Process}

During the injection molding, the plastic material is heated until it forms a uniform melt, which will then be introduced into in the mold cavity. Once the cavity is nearly completely filled, compacting pressure is applied to fill the cavity's remaining volume. This pressure needs to compensate for material cooling shrinkage. Once the material at the cavity's entry solidifies, the process of cooling the entire part through heat exchange with the surrounding air starts. The heat transfer with the cooling system cools the whole room. When the part is sufficiently rigid to be removed from the mold cavity, it is ejected, and the process is restarted. Mold configuration is an important factor in the final product quality. The type of mold used influences its strength, durability, form, and dimensions. The mold must be strong enough to resist the pressures encountered during the molding process. In addition, the polymer should be able to correctly flow all along mold cavity. In order to control the cooling process, the mold should be cautiously created to allow heat transfer [2].

Mold cooling has an impact on critical sizes, surface quality, and cycle time. As a result, mold cooling is a critical factor in producing a high-quality product at a reasonable price. To remove the heat produced by the molten material, the mold should be cooled, or heated if compared to room temperature, with a heat exchange system, also known as a temperature control unit. The cooling process begins immediately after the molten polymer is injected. However, the cooling duration is defined as the time between the gate solidifying, when the holding stage is completed, and the part being ejected once it has reached a temperature low enough to resist the forces during ejection. The proximity of the coolant contributes significantly to the cooling system efficiency. Conformal cooling allows the channels to be placed close to the cavity's surface, allowing heat to be transported more quickly. The primary goal of conformal cooling is to accomplish a uniform heat field in the mold and the cavity. This consistency both prevents and reduces warping after part ejection [3].

\subsubsection{Temperature Control}

Temperatures of the molten material, the mold, the environment, and, thus, the clamping system must be monitored (Fig. 2).
Once the molten polymer has been injected into the mold, its solidification is necessary for the object forming. The temperature of the mold is controlled by circulating a coolant, typically water or oil, via channels inside the mold parts. The part can be ejected after it has been sufficiently cooled. The majority ( 95 percent) of the shrinkage occurs inside the mold and, therefore, is compensated for by the input materials; the remaining shrinkage occurs after the part is manufactured.

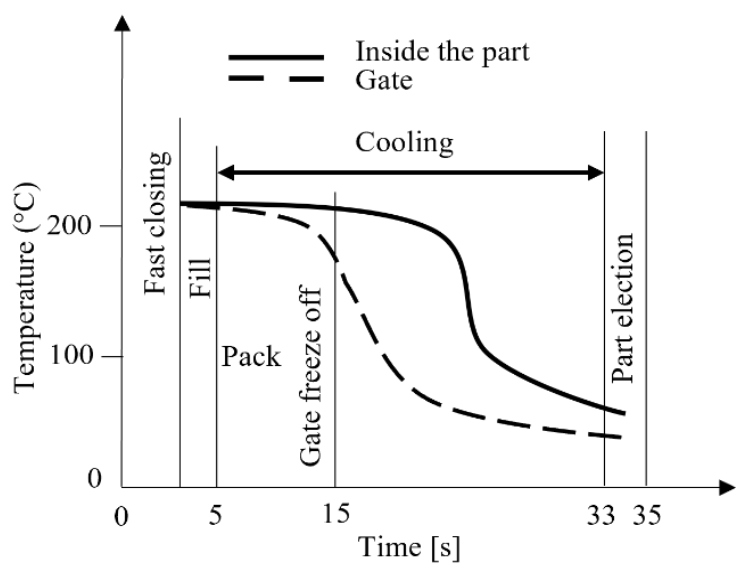

Fig. 2. Temperature data from injection molding [4]

\subsubsection{Pressure Regulation}

Pressure is applied by both the injection unit and the clamping system, with the latter designed to withstand the former (Fig. 3).

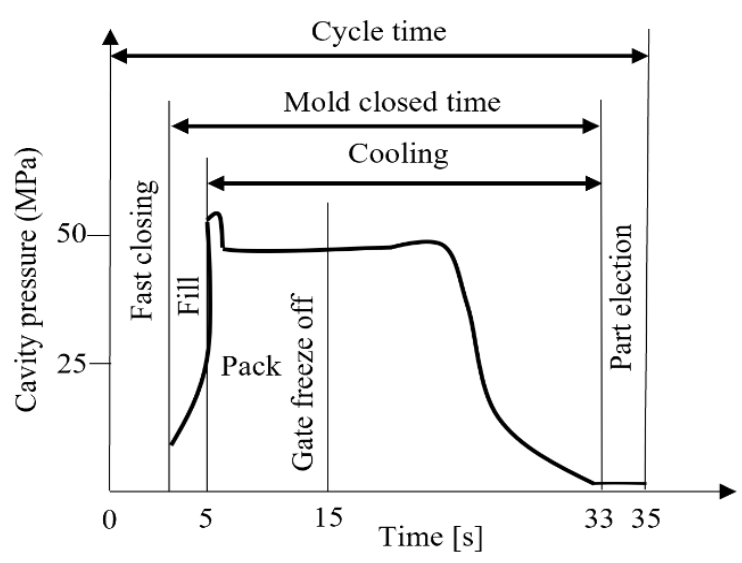

Fig. 3. Pressure history during injection molding [4]

There are three distinct pressures in the injection unit: initial, hold, and return pressure. These are accomplished through the movement of a screw. The oil pump in the hydraulic system regulates the pressure required to move the mold in the clamping unit. To compensate for shrinkage, holding pressure is needed for the filling operation and should be preserved throughout solidification. 


\subsubsection{Time Control}

The total time spent on the molding cycle determines the process profitability, the most important step is the cooling phase. The length of time spent on the cooling cycle determines the rate of production of parts. Because time and cost are closely related in most modern industries, the longer the time it takes to produce parts, the greater the costs. Reducing the amount of time spent in cooling the part would significantly increase the production rate and lower the costs. As a result, understanding and optimizing the heat transfer in molding process is critical. A basic diagram depicting the cycle time is provided in (Fig.1).

\subsubsection{Thermal Characteristics}

The thermal properties are to control starting with the injection of the molten material into the mold cavity until it cools. In fact, because these properties actually impact the final product quality, it is critical to have a solid understanding of the materials used for both the mold and the plastic. This factor describes a material's ability to circulate heat throughout a system, resulting in a temperature difference. It is based on thermal exchanges. The Fourier law assists in understanding the behavior of heat between the cavity and the cooling systems, as well as heat convection within the cooling channels. To that end, simulation studies were carried out for this study [1], [4].

\subsection{History of Cooling Channels Design}

Rapid prototyping and tooling manufacturing processes have been widely used in recent years to accelerate tooling and production. These processes significantly decrease manufacturing costs as well as the time necessary for tolling production. Figure 4 depicts the distinction between traditional tooling fabrication and modern rapid tooling manufacturing which can be applied in the fabrication of injection molds.
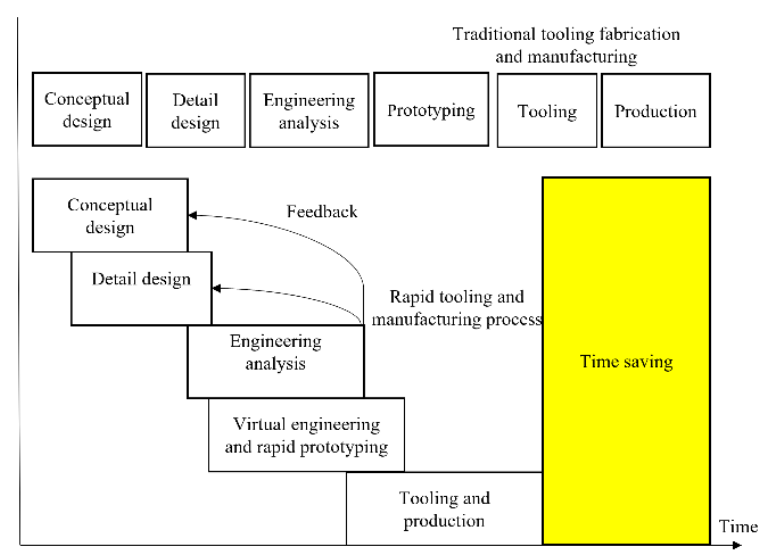

Fig. 4. Time difference between traditional and rapid tooling manufacturing [5]

\subsubsection{Conventional Cooling Channels}

A traditional cooling channel circulates coolant through the plastic mold cavity, dissipating thereby heat. This is the most common way to regulate mold temperature. The channel is produced by making holes of varying sizes as near to the cavity's existing molding area as possible. Drilled holes always are manufactured with a drill or boring machine, depending on the required tool geometry of the part. The side wall of the mold is plugged and the coolant flows into the channels and changes direction as it follows the cross holes. A straight cooling pattern surrounds the free-form geometric cavity. As a result, the mold area will cool unevenly due to the different distances to the cooling channels.

\subsubsection{Conformal Cooling Channels}

Conformal cooling is a cooling system which conforms to the surface of the mold cavity (or core) to transfer the heat efficiently from of the mold cavity to the coolant. The term conforming refers to the cooling channel's geometry matching the geometry of the mold surface (Fig. 5). The goal is to keep the molded part's cooling performance consistent and uniform. According to the findings of several studies [6], [7], [8], [9], [10], the cooling performance of the injection mold since using conformal cooling systems can provide a more uniform heating in the mold than the conventional cooling system. The conformal cooling channel allows heat to be transferred or dissipated uniformly. However, such complex channels cannot be produced using traditional machining processes.

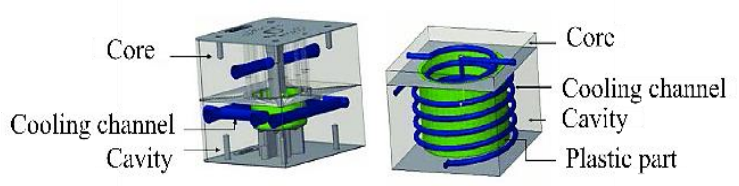

Fig. 5. An example of representation of a traditional mold (on the left) and a mold with 3D printed conformal cooling (on the right) [5]

The use of cooling systems that conform to the molding cavity improves mold temperature control as well as part dimensions control. In the 1990s, a group at MIT reported on this [11]. MIT's Xu and Sachs presented a thorough, modular method for designing conformal cooling channels. They realized that cooling was restricted to the tool surface and divided the tool into various geometrical areas, each with its own channel system. Mold cavity surface temperature, pressure drop, mold material properties, and other design parameters were taken into account in their research [11], [12]. Three-dimensional printing was used to directly fabricate tooling from metal powders. They improved temperature control, dimensional control, surface finishing, and tool hardening by 
implementing additive manufacturing processes. They were working with stainless steel powder, which led to a tooling hardness of 25-30 Rockwell C [13].

Ferreira and Mateus reviewed rapid soft tooling for the injection molding process. Their study's main goal was to propose some novel approaches to create injection molding process tools by combining advanced production technologies with composite materials cooled by conformal cooling [14].

Meckley and Edwards also discussed the effects of conformal cooling channels on cooling time and part quality when opposed to conventional cooling systems [15]. In their study, they used high density polyethylene and polycarbonate and demonstrated the mold and melt temperature differences between the two materials to show conformal channel efficiency.

Wang et al. created an automated method for designing conformal cooling circuits by establishing a link between the conformal cooling and the plastic body shape [16].

In 2011, Au and Yu introduced an approach for automatic preliminary cooling system design called "visibility-based cooling channel generation". This strategy is more geometric and theoretical than one that would be used in a practical scenario [17]. Following that, in 2014, they introduced a cooling system distance modification predicated on adjustment direction and adjustment quantity. In addition, a modelling approach utilizing Moldflow Plastic Insight has been used to evaluate the viability of their suggested technique [18].

Agazzi et al. suggested "Morpho Cooling" a novel approach for designing cooling channels in molded products. This strategy resulted in better cooling results of temperature homogeneity and less part warpage [19].

Despite the fact that multiple researches on the analysis of conformal cooling channels have been conducted, there has been very few research on the design parameters of conformal systems for various types of part design. Until recently, the most of designs were developed based on the designers' previous experiences. Furthermore, according to the author's knowledge, it is unusual to find a combination of design parameters, cross section size, and experimental evaluations. However, some initial literature information could be collected to be used as a foundation for future research in this area. For example, Mayer found a straightforward correlation between various parameters for the design of conformal cooling channels that were fabricated using $3 \mathrm{D}$ printing [20].

\section{INJECTION MOLDING ANALYSIS}

\subsection{Presentation of the Industrial Case}

In what follows, the work is based on an industrial case in collaboration with the company "Injection Plastiques Systèmes (IPS)" specialized in the manufacture of plastic injection parts for the automotive industry, electrical, electronic and household appliances. The company gave us access to documents related to the product, its mold, and the specified injection machine. The objective of this work is to redesign the cooling system of a mold that produces filter bases for automotive industry (Fig. 6) to meet the company's requirements.

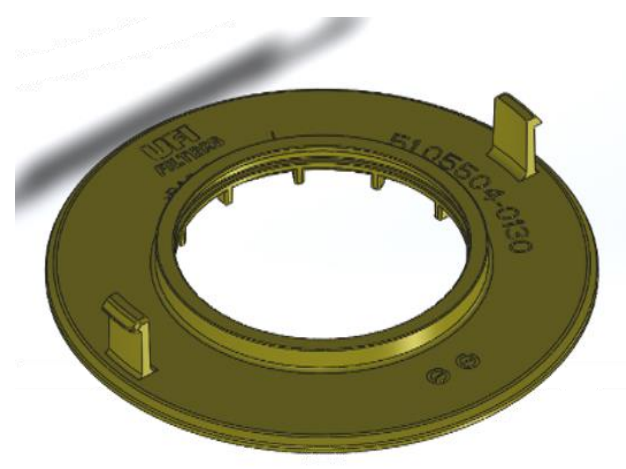

Fig. 6. Filter base (2 pieces/mold)

The product is a filter base ( 2 pieces/mold) from the material PA6 $30 \%$ GF BKV130. The process is a standard process with a 3-plates mold. The number of imprints is 2. The current mold design contains six traditionally machined baffle channels in the mold cavity core insert (moving moud half), and six baffle cooling channels in the cavity plate (fixed mold half).

\subsection{Analysis of the old Traditional Cooling System}

This Filter base has a high cooling time of $20 \mathrm{~s}$ and, therefore, a high cycle time of $\approx 34 \mathrm{~s}$. In addition, the product has a deformation of $1.6 \mathrm{~mm}$ (planarity problem) due to the non-homogeneous cooling. The analysis's goal is to reduce cycle time and improve product quality by improving temperature uniformity and reducing deflection and warping effects.

We notice that the channels on the cavity side and the channels on the core side have punctual contact with the part, which decreases the exchange surface and, consequently, increases the cooling time. Figure 7 shows the existing traditional cooling channels.
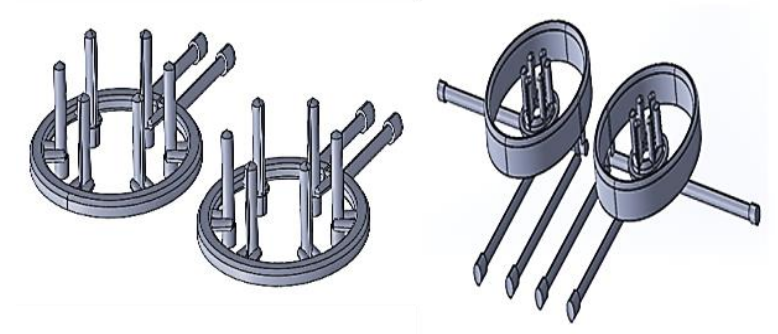

Fig. 7. Conventional upper (left) and lower (right) cooling channels 


\subsection{Determination of the Model Parameters and Design of the Conformal Cooling}

The choice of the right type of cooling channel for this investigation is critical. The plastic part's geometry should be used to make the decision. Since the mold is large and the plastic part is principally flat in form, the ancient mold's main cooling channels were kept. We upgraded the existing cooling channels by incorporating new circular cooling channels. Optimizing the injection cycle consists in reducing the cycle time. This is done in two ways:

- Increasing the cooling channel's diameter (i.e., the number of channels).

- Reducing the distance between the cooling system and the cavity wall.

Due to the design constraints of the three-plate tooling, the mold cavities and the small size of the workpiece, research was done to retain the shape of the cavities as well as its dimensions by using a new conformal channel design.

To realize the new design of the existing cooling system using conformal channels, the model parameters such as the diameter $\mathrm{D}$, the distance between two channel axes $\mathrm{P}$ (pitch distance), and the wall to channel distance L (centerline channel to mold wall distance) should first be defined. These parameters could be determined using the Mayer's table [16].

The average thickness of the part is between 2 and $4 \mathrm{~mm}$. First, a diameter $\mathrm{D}=8 \mathrm{~mm}$ identical to the one used in the existing mold was selected to compare the results of the new model with the conventional model. Depending on the correlations between conformal cooling channel design parameters [20], P and $\mathrm{L}$ were calculated. The pitch distance $\mathrm{P}=2 * 8=$ $16 \mathrm{~mm}$ and the wall to channel distance $\mathrm{L}=1.5 * 8=$ $12 \mathrm{~mm}$. Table 1 presents the channel design parameters.

Table 1. Correlations between design parameters for the conformal cooling channel [20]

\begin{tabular}{|c|c|c|c|}
\hline $\begin{array}{c}\text { Part wall } \\
\text { thickness [mm] }\end{array}$ & $\begin{array}{c}\mathbf{D} \\
{[\mathbf{m m}]}\end{array}$ & $\begin{array}{c}\mathbf{P} \\
{[\mathbf{m m}]}\end{array}$ & $\begin{array}{c}\mathbf{L} \\
{[\mathbf{m m}]}\end{array}$ \\
\hline $0-2$ & $4-8$ & 2D-3D & $1.5 \mathrm{D}-2 \mathrm{D}$ \\
\hline $2-4$ & $8-12$ & 2D-3D & $1.5 \mathrm{D}-2 \mathrm{D}$ \\
\hline $4-6$ & $12-16$ & 2D-3D & $1.5 \mathrm{D}-2 \mathrm{D}$ \\
\hline
\end{tabular}

Given the circular shape of the part, the design of the channels is circular. The new model is made using SolidWorks software.

It is known that by increasing the diameter of the cooling channel, the cycle time will decrease as well as the cooling time. For this, we tried to increase the diameter in order to keep the shape of the cavities.

The solution is to keep the internal channels ( 4 channels in the lower part, 2 for each part) with an 8 $\mathrm{mm}$ diameter, and to change the diameter of the external channels ( 4 channels: 2 upper and 2 lower, 2 channels for each part) to $10 \mathrm{~mm}$. As well as making small modifications on the design.

The number of channels is limited due to dimensional constraints and the shape of the cavity (no change in size or shape is applied to the mold components). Figure 8 presents the new design of the conformal cooling channels.

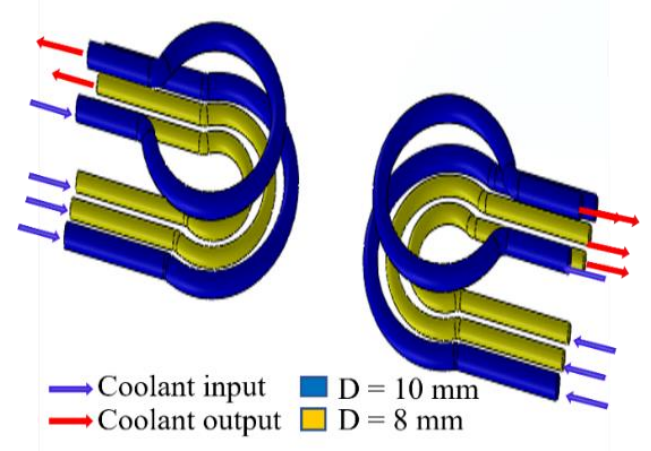

Fig. 8. New conformal cooling channels for the production of 2 parts in the mold

\subsection{Analytical Approach on Cooling System Design}

\subsubsection{Determination of Cooling Time}

The minimum cooling time of a cast part with regular geometry in plate form can be calculated using analytical solutions in one dimension to the heat transfer equation (Menges et al) [11]:

$$
\mathrm{T}_{c m}=\frac{s^{2}}{\alpha_{p} \cdot \pi^{2}} \ln \left(\frac{4 \cdot\left(\mathrm{T}_{i}-\mathrm{T}_{w}\right)}{\pi \cdot\left(\mathrm{T}_{e}-\mathrm{T}_{w}\right)}\right)
$$

where $\mathrm{T}_{\mathrm{cm}}$ - minimum cooling time (s), $s$ - thickest part thickness $(\mathrm{m}), \mathrm{t}_{\mathrm{i}}$ - injection temperature $\left({ }^{\circ} \mathrm{C}\right), \mathrm{T}_{\mathrm{w}}$ - mold wall temperature $\left({ }^{\circ} \mathrm{C}\right.$ ) (considered to be equal to the temperature of the coolant), $\mathrm{T}_{\mathrm{e}}$ - demolding temperature $\left({ }^{\circ} \mathrm{C}\right), \alpha_{\mathrm{p}}$ - thermal diffusivity of the molding material $\left(\mathrm{m}^{2} / \mathrm{s}\right)$.

$$
\alpha_{p}=\frac{K_{p}}{C_{p} \cdot \rho}
$$

where $K_{p}$ - thermal conductivity of the molding material $\left(\mathrm{W} / \mathrm{m}^{\circ} \mathrm{C}\right), \mathrm{C}_{\mathrm{p}}$ - specific thermal capacity of the part material $\left(\mathrm{J} / \mathrm{kg}^{\circ} \mathrm{C}\right), \rho$ - density of the material $\left(\mathrm{kg} / \mathrm{m}^{3}\right)$.

Numerical application:

$$
\alpha_{p}=\frac{0.25}{1470 \cdot 1360}=1.25 \cdot 10^{-7} \mathrm{~m}^{2} / \mathrm{s}
$$

$\mathrm{T}_{\mathrm{i}}=290^{\circ} \mathrm{C}, \mathrm{T}_{\mathrm{w}}=80^{\circ} \mathrm{C}$ (IPS data), $\mathrm{T}_{\mathrm{e}}=210^{\circ} \mathrm{C}$ (simulation), $\mathrm{s}=0.00936 \mathrm{~m}$ (SolidWorks). 


\subsubsection{Evaluation of the Required Heat Transfer Rate}

After determining the cooling time, the total heat of the part to be eliminated by the cooling system can be calculated when thermal equilibrium was reached. The heat flow into the mold and the heat flow out of the mold should be balanced [21]:

$$
Q_{p}=Q_{c}
$$

where:

$$
\begin{aligned}
& Q_{p}=m_{p} \cdot C_{p} \cdot\left(T_{i}-T_{e}\right) \\
& Q_{c}=m_{c} \cdot C_{c} \cdot \Delta T_{c}
\end{aligned}
$$

where $Q_{p}$ - heat flow transferred into the mold $(\mathrm{J}), \mathrm{Q}_{\mathrm{c}}$ heat flow removed from the mold $(\mathrm{J}), \mathrm{T}_{\mathrm{i}}$ - injection temperature $\left({ }^{\circ} \mathrm{C}\right), \mathrm{T}_{\mathrm{e}}$ - demolding temperature $\left({ }^{\circ} \mathrm{C}\right)$, $\mathrm{m}_{\mathrm{p}}$ - mass of the part $(\mathrm{kg}), \mathrm{C}_{\mathrm{p}}$ - specific thermal capacity of the part material $\left(\mathrm{J} / \mathrm{kg}{ }^{\circ} \mathrm{C}\right), \mathrm{m}_{\mathrm{c}}$ - mass of the cooling channel $(\mathrm{kg}), \mathrm{C}_{\mathrm{c}}$ - specific thermal capacity of the coolant $\left(\mathrm{J} / \mathrm{kg}{ }^{\circ} \mathrm{C}\right), \Delta \mathrm{T}_{\mathrm{c}}$ - allowable temperature increase of the coolant $\left({ }^{\circ} \mathrm{C}\right)$.

Numerical application:

$\mathrm{m}_{\mathrm{p}}=67.46 \cdot 10^{-3} \mathrm{~kg}$ (SolidWorks), $\mathrm{C}_{\mathrm{p}}=1470 \mathrm{~J} / \mathrm{kg}^{\circ} \mathrm{C}$, $\mathrm{T}_{\mathrm{i}}=290{ }^{\circ} \mathrm{C}, \mathrm{T}_{\mathrm{e}}=210{ }^{\circ} \mathrm{C}($ IPS data);

$\rightarrow \mathrm{Q}_{\mathrm{p}}=7933.3 \mathrm{~J}, \mathrm{Q}_{\mathrm{c}}=7933.3 \mathrm{~J}$.

The volumetric flow rate of the required coolant must be able to absorb the heat from the polymer while avoiding an excessive increase of its temperature to ensure an identical cooling of the assembly. The minimum fluid flow rate can, therefore, be estimated as [21]:

$$
V_{c}=\frac{Q_{c l}}{\Delta T_{c} \cdot T_{c m} \cdot \rho_{c} \cdot C_{p c}}
$$

where: $\mathrm{V}_{\mathrm{c}}$ - minimum fluid flow rate $\left(\mathrm{m}^{3} / \mathrm{s}\right), \mathrm{Q}_{\mathrm{cl}}$ - heat to be absorbed by a cooling channel $(\mathrm{J}), \Delta \mathrm{T}_{\mathrm{c}}$ allowable temperature increase of the coolant $\left({ }^{\circ} \mathrm{C}\right), \rho_{\mathrm{c}}$ - density of the coolant $\left(\mathrm{kg} / \mathrm{m}^{3}\right), \mathrm{T}_{\mathrm{cm}}$ - minimum cooling time $(\mathrm{s}), \mathrm{Cp}_{\mathrm{c}}-$ specific heat capacity of the coolant $\left(\mathrm{J} / \mathrm{kg}^{\circ} \mathrm{C}\right)$.

Assuming that we have for a cavity 2 channels, on the cavity side 1 channel and on the core side 1 channel:

Table 3. Filling pressure versus time

\begin{tabular}{|c|c|}
\hline Time [s] & Filling pressure [MPa] \\
\hline 0.2 & 100 \\
\hline 2 & 60 \\
\hline 8 & 60 \\
\hline
\end{tabular}

$$
\begin{aligned}
& Q_{c l}=Q_{c} / 2 \\
& V_{c}=\frac{Q_{c l}}{2 \cdot \Delta T_{c} \cdot T_{c m} \cdot \rho_{c} \cdot C_{p c}}
\end{aligned}
$$

Numerical application:

$\mathrm{Q}_{\mathrm{c}}=7933.3 \mathrm{~J}$ (calculated), $\Delta \mathrm{T}_{\mathrm{c}}=3^{\circ} \mathrm{C}, \mathrm{t}_{\mathrm{cm}}=13.92(\mathrm{~s})$, $\rho_{\mathrm{c}}=997 \mathrm{~kg} / \mathrm{m}^{3}, \mathrm{C}_{\mathrm{pc}}=4180 \mathrm{~J} / \mathrm{kg}^{\circ} \mathrm{C}$;

$\rightarrow \mathrm{Vc}=22.7 \mathrm{~cm}^{3} / \mathrm{s}$.

\subsubsection{Determination of the Diameter of the Cooling Channels}

The channels' maximum diameter must be chosen in such a way that a turbulent flow is ensured for a volumetric flow rate of the coolant $\mathrm{V}_{\mathrm{c}}$. For this, the Reynolds number $R_{e}$ must be high enough ( $>>2000$ ) [21].

$$
R_{e}=\frac{V_{c} \cdot D_{h}}{v_{c}}
$$

where $\mathrm{R}_{\mathrm{e}}$ : Reynolds number, $v_{\mathrm{c}}$ - kinematic viscosity of the cooling fluid $\left(\mathrm{m}^{2} / \mathrm{s}\right)$.

$$
\mathrm{v}_{c}=\frac{\mu_{c}}{\rho_{c}}
$$

$\mu_{\mathrm{c}}$ - dynamic viscosity of the cooling fluid (Pa.s), $\rho_{\mathrm{c}}$ density of cooling fluid $\left(\mathrm{kg} / \mathrm{m}^{3}\right), \mathrm{D}_{\mathrm{h}}$ - hydraulic diameter ( $\mathrm{mm})$.

$$
D_{h}=\frac{4\left(\frac{\pi \cdot D_{C}^{2}}{4}\right)}{\pi \cdot D_{c}}=D_{c} \quad \text { (circular channels) }
$$

The Maximum channel diameter $\mathrm{D}_{\text {cmax }}$ can be determined as follows:

$$
\begin{aligned}
& R_{e} \gg \frac{\rho_{c} \cdot V_{c} \cdot D_{\text {max }}}{\mu_{c}} \\
& D_{c \max } \ll \frac{\rho_{c} \cdot V_{c}}{R_{e} \cdot \mu_{c}}
\end{aligned}
$$

Numerical application:

$\rho_{\mathrm{c}}=997 \mathrm{~kg} / \mathrm{m}^{3}, \mu_{\mathrm{c}}=10^{-3}$ Pa.s, $\mathrm{R}_{\mathrm{e}}=2000, \mathrm{~V}_{\mathrm{c}}=22.7 .10^{-}$ ${ }^{6} \mathrm{~m}^{3} / \mathrm{s}$;

$\rightarrow \mathrm{D}_{\mathrm{cmax}}=11.31 \mathrm{~mm}$.

\section{MOLDFLOW SIMULATION}

The simulation is performed by Moldflow Insight software which is a CAD software used for validation and optimization of mold design. Before proceeding to the analysis, the process was parameterized (Tables 2 and 3 ).

Table 2. Injection parameters

\begin{tabular}{|l|c|}
\hline Temperature of the material & $290^{\circ} \mathrm{C}$ \\
\hline Mold temperature & $80{ }^{\circ} \mathrm{C}$ \\
\hline Mold opening/closing time & $5 \mathrm{~s}$ \\
\hline Ejection temperature & $210^{\circ} \mathrm{C}$ \\
\hline Ambient temperature & $25^{\circ} \mathrm{C}$ \\
\hline Injection time & $2.5 \mathrm{~s}$ \\
\hline
\end{tabular}




\subsection{Creation of the Model}

The simulation model was created as follows:

- Model meshing: After importing the part to Moldflow Insight, we used for this modeling a volume mesh of size $2 \mathrm{~mm}$. The volume mesh has been used for meshing, because the thickness of the part is $5 \mathrm{~mm}$.

- $\quad$ Choose the type of tasks: In our case, we have to select the program options according to our task (mold thermal $($ FEM $)+$ filling + compacting + gauging + the kind of injected material).

- Importing the cooling circuit: We imported this system in two stages: the upper part and then the lower part, and each time we chose the point of entry and the point of exit, as well as the properties of the cooling fluid (flow rate: 23 $\mathrm{cm}^{3} / \mathrm{s}$; water temperature: $25^{\circ} \mathrm{C}$ ). Figure 9 shows the part with the cooling circuit and the points of entry/exit of water.

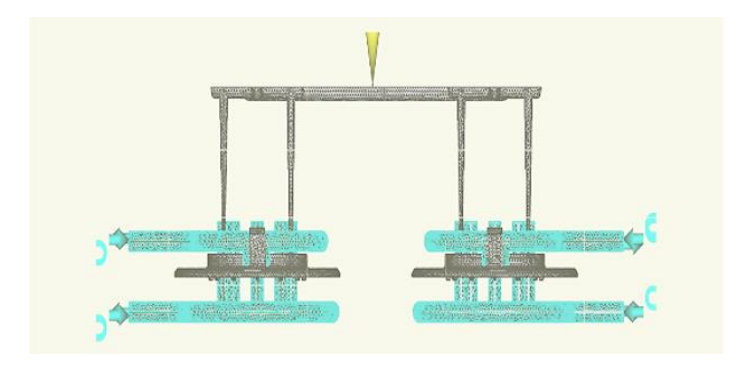

Fig. 9. Numerical model

- Creation of the components of the mold (mold block): A mold block was created with dimensions equal to those of the existing block.

- Mesh of the cooling circuit and mesh of the mold block: For this modelling, we used a volume mesh of size $5 \mathrm{~mm}$. The meshing of the mold block was done in two steps: first surface meshing and then volume meshing.

- $\quad$ Setting all injection parameters: Finally, all parameters (mold temperature, mold opening time, mold closing time before injection, filling pressure vs. time) were set. Table 4 gives all numerical details of the model.

Table 4. Numerical details of the model

\begin{tabular}{|l|l|}
\hline Type of mesh & Tétas 3D \\
\hline Number of part elements & 916737 \\
\hline Number of channel elements & 509371 \\
\hline Number of mold elements & 2762004 \\
\hline Total volume & $93.4706 \mathrm{~cm}^{3}$ \\
\hline Volume of the part to be filled & $70.8563 \mathrm{~cm}^{3}$ \\
\hline $\begin{array}{l}\text { Volume of channel / threshold to be } \\
\text { filled }\end{array}$ & $22.5777 \mathrm{~cm}^{3}$ \\
\hline Total mass & $115.7753 \mathrm{~g}$ \\
\hline Mass of two parts & $87.2019 \mathrm{~g}$ \\
\hline Mass of supply channels / thresholds & $28.5734 \mathrm{~g}$ \\
\hline
\end{tabular}

\subsection{Results and Discussion}

\subsubsection{Cooling Time}

The conformal circuit, in which the diameter of the outer channels has been increased to $10 \mathrm{~mm}$, gives more efficient results in terms of cooling time which decreases from $20 \mathrm{~s}$ to $14.02 \mathrm{~s}$ (Fig. 10).

Time to reach ejection temperature, part Time $=14.02[\mathrm{~s}]$

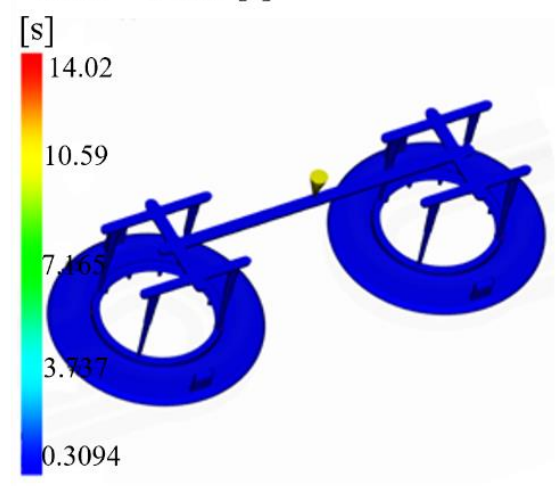

Fig. 10. Time to reach ejection temperature, conformal circuit

\subsubsection{Coolant Temperature of the Circuit}

Figure 11 displays the coolant temperature results within the cooling system. The coolant's temperature is proportional to the flow rate and pressure in the circuit. The maximum temperature difference between the circuit's inlet and outlet is $4{ }^{\circ} \mathrm{C}$ (input temperature = $25^{\circ} \mathrm{C}$ and output temperature $=29^{\circ} \mathrm{C}$ ).

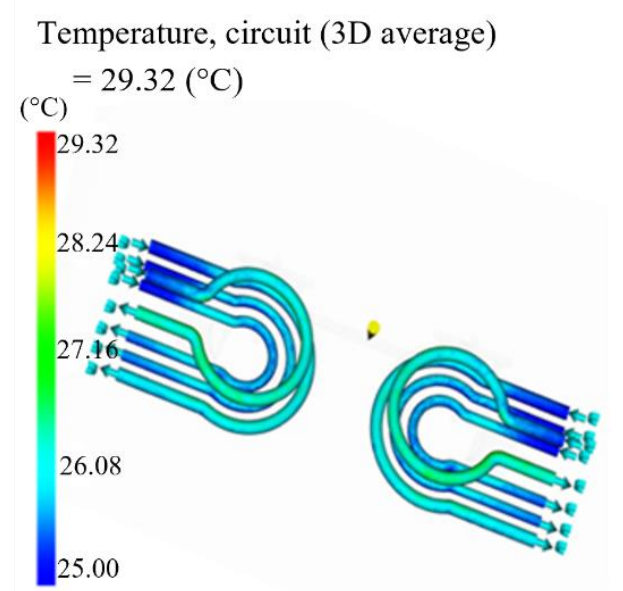

Fig. 11. Cooling system temperature of the conformal circuit

This is due to the fact that the temperature of the coolant varies throughout the circuit. The temperature at the outlet channel was higher than the temperature along the circuit, and this variation happened linearly 
in the conformal circuit. However, the conventional circuit has an input coolant water temperature of $25^{\circ} \mathrm{C}$ and an output temperature of $40{ }^{\circ} \mathrm{C}$ which makes a difference of $14{ }^{\circ} \mathrm{C}$. The temperature difference of the coolant in conformal circuit is small, so the number of the proposed new circuits is sufficient.

\subsubsection{Mold Temperature}

Figure 12 depicts the mold's surface temperature during the cycle. The conformal circuit, in fact, had the highest efficiency and promoted uniform cooling around the mold, compared to the old system that has different temperatures in the mold surface. Temperatures in the majority of the part-maintained areas were about $30^{\circ} \mathrm{C}$ (the figure's blue color).

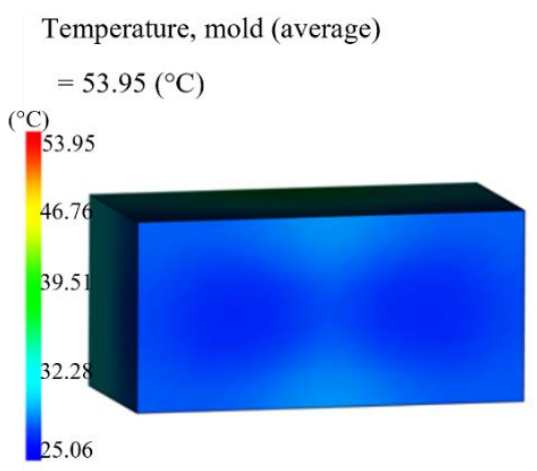

Fig. 12. Mold surface temperature, conformal circuit

Achieving a satisfactory system cooling efficiency demands a uniform heating in this interface with no hot zones, and that's a major cause of stress and warpage in the plastic product. So, when the interface cools evenly with minor temperature variations, the possibility of defects is reduced, and the part quality will improve.

\subsubsection{Injection Pressure}

Figure 13 shows that the conformal circuit provides a low injection pressure of $42.82 \mathrm{MPa}$. High pressures are not preferred, so injection pressure is an important factor in determining whether a cooling system is viable. This circuit is optimal and economic.

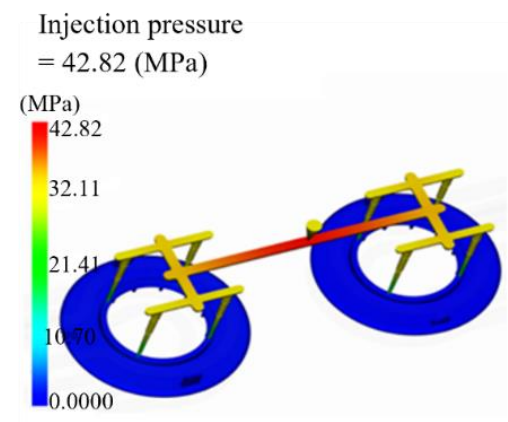

Fig. 13. Injection pressure, conformal circuit

\subsubsection{Filling Time}

The studies show that the filling time is balanced for both cavities. Figure 14 shows that the filling time is $3.065 \mathrm{~s}$ and the flow state is balanced. The time of conformal cooling is the same as for conventional cooling and is, therefore, not a problem.

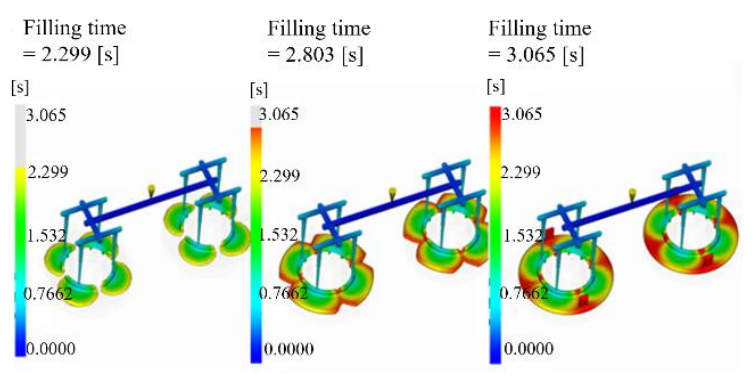

Fig. 14. Filling time at different moments, conformal circuit

\subsubsection{Defect results}

Most defects appearing in injection molding are air bubbles, welding lines, and volumetric shrinkage.

- Air bubbles: An air bubble is air that is trapped inside the mold cavity. The air bubbles are located in the end zones of filling, more precisely at the parting line, so we can easily escape the air from the parting line with the help of a venting system and two pins in the cavity, one in the mobile part and the other one in the fixed part of the tool. Figure 15 shows that with the new system no other problems occur. The part quality is not affected.

- Welding lines: The weld lines (Fig. 16) are located at the intersection of the material flows during the filling process (there are 4 injection points for one part). In our case, most of their traces are located at the junction between the drawers. Weld lines and air bubbles are all located in inconspicuous areas, so not affecting the appearance of the part. Some weld lines may affect the strength of the molded part, this effect can be reduced by moving the location of the injection points. This will require the modification of the cavity feeding system.

- Volumetric shrinkage: The volumetric shrinkage is the difference between the specific volume of the material at the time of solidification of the gate and the specific volume of the material at room temperature.

According to figure 17, volumetric shrinkage has been balanced. To reduce warpage, it should be uniform all across the part.

Part deflection: Differential cooling effects are defined as warpage caused by shrinkage differences in thickness (from the cavity to the core. 


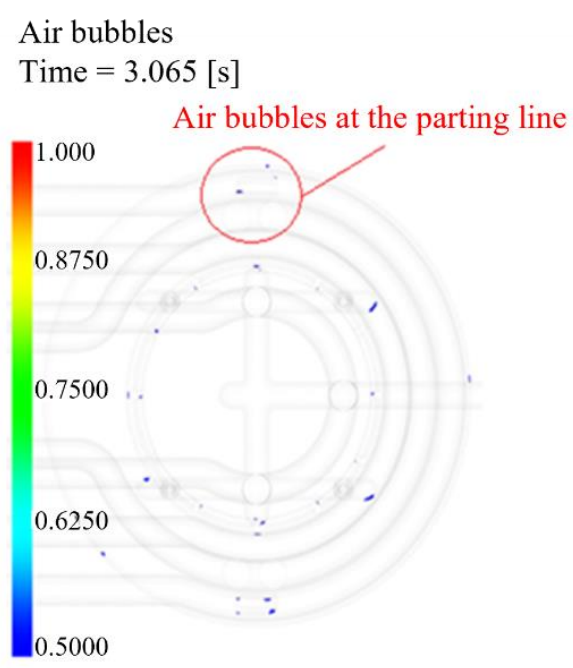

Fig. 15. Air bubbles, conformal cooling

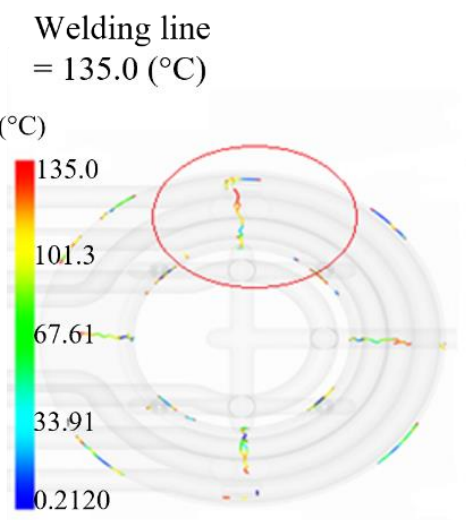

Fig. 16. Welding lines, conformal cooling

$$
\begin{aligned}
& \text { Volumetric shrinkage } \\
& \text { Time }=14.02[\mathrm{~s}]
\end{aligned}
$$

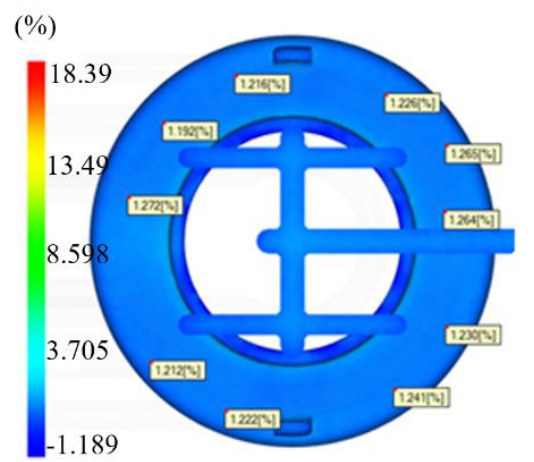

Fig. 17. Volumetric shrinkage, conformal cooling

The product deflection after the injection was also simulated using the cooling design shown in (Fig.18). According to the figure, the deformation in all directions is decreased. In fact, the conformal cooling system causes a $0.5 \mathrm{~mm}$ deflection inside the product cavities and in its center. Conformal cooling circuits in the mold result in more or less homogeneous cooling around the mold, and consequently allows a lower deflection compared to that with conventional cooling circuits, in which a deformation of $1.6 \mathrm{~mm}$ was measured. Comparing these results, we can see that the deformations in all $\mathrm{X} / \mathrm{Y} / \mathrm{Z}$ directions decrease when using the new conformal circuit, which reduces the warpage by $68.75 \%$. The customer demands a maximum workpiece flatness tolerance of $0.3 \mathrm{~mm}$, so there is still research potential regarding this property.

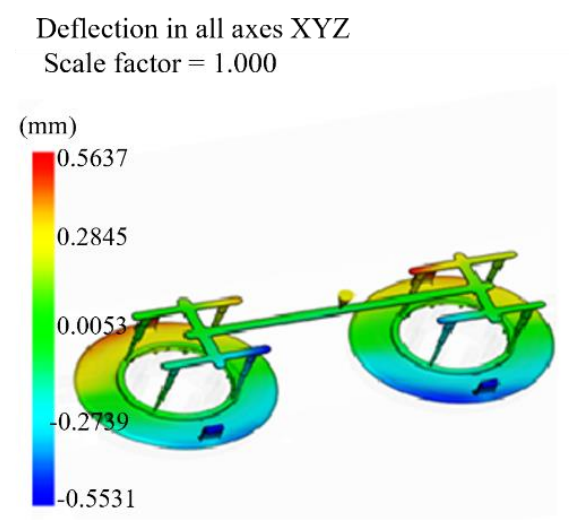

Fig. 18. Deflection in all axes $X Y Z$

\subsection{Benefits of the Conformal Circuit}

The cooling time decreases from $20 \mathrm{~s}$ to $14.02 \mathrm{~s}$ and, consequently, the cycle time decreases from 34 s to 28 s. $6 \mathrm{~s}$ are gained in one cycle in conformal cooling. The economic benefit can be calculated as follows:

- $\quad$ Production time of the IPS per week: 3 x (8 x 5) + $4=124$ hours ( 3 shift groups working 8 hours/day from Monday up to Friday and 4 hours on Saturday).

- Quantity produced per week with the conventional circuit: $\mathrm{Q}_{\mathrm{conv}}=$ (production time $/$ week) $/($ cycle time of a part $)=124 \times 3600 / 34=13130$ parts/week.

- $\quad$ Quantity produced per week with the conforming circuit: $\mathrm{Q}_{\text {conf }}=($ production time/week $) /($ cycle time of a part $)=124$ x $3600 / 28=15943$ parts $/$ week.

- $\quad$ Quantity profited per week: $\mathrm{Q}_{\mathrm{conf}}-\mathrm{Q}_{\mathrm{conv}}=2813$ pieces/week.

- Amount of profit: $2813 \times 0.2722 € /$ piece $=765.70$ $€ /$ week $=3062.80 € /$ month or $36753 € /$ year.

Even when the manufacturing of the conformal tool by additive manufacturing costs around $6000 €$ more than a conventional tool, a profit of about 30000 $€$ per year will be made.

\section{CONCLUSIONS}

Cooling is a critical subprocess in injection molding process, accounting for roughly $60 \%$ of the total process time and having a direct impact on shrinkage as well as the warpage of the molded plastic product. As a result, the design of an effective cooling channel 
system in the mold is critical, as it impacts production capacity, quality, and cost.

Moldflow thermal simulation results show that with appropriate geometric cross-sections and layout designs, conformal cooling channels have the potential to reduce cooling rates up to $30 \%$, As a result, the production rate and quality of injection molded parts have been significantly improved.

The result of the thermal analysis showed that the cycle time was reduced from $34 \mathrm{~s}$ to $28 \mathrm{~s}$ (about $30 \%$ ) and an almost uniform temperature distribution of the complete injection mold assembly was achieved by using conformal cooling channels.

The weld line trace and air bubbles are all located in inconspicuous places, so not affecting the appearance of the part and the air bubbles are easily vented.

The deformation caused by the differential cooling effect is uniform. The deflection in the XYZ axes was reduced from $1.6 \mathrm{~mm}$ to $0.5 \mathrm{~mm}$ (about 69\%). As a result, conformal cooling for the injection molding process is an intriguing option for improving plastic product quality and decreasing cycle time and cost.

\section{REFERENCES}

[1] Dimla E., Design considerations of conformal cooling channels in injection moulding tools design: an overview, Journal of Thermal Engineering SPECIAL ISSUE 2 Energy Systems and Developments 2015 ICESD 2015 INDIA (7), pp. 627-635.

[2] Jahan S. A., Wu T., Zhang Y., Zhang J., Tovar A., Elmounayri H., Thermo-mechanical design optimization of conformal cooling channels using design of experiments approach, Procedia Manufacturing, volume 10, 2017, pp. 898-911.

[3] Vojnová E., The benefits of a conforming cooling systems the molds in injection moulding process, Procedia Engineering 149, 2016, pp. 535-543.

[4] Dimla E., Camilotto M., Miani F., Design and optimisation of conformal cooling channels in injection moulding tools, Journal of Materials Processing Technology 164 (5), 2005, pp. 1294-1300.

[5] Au K.M., Yu K.M., A scaffolding architecture for conformal cooling design in rapid plastic injection moulding, The International Journal of Advanced Manufacturing Technology, volume 34, 2007, pp. 496-515.

[6] Feng S., Kamat A. M., Design and fabrication of conformal cooling channels in molds: Review and progress updates, International Journal of Heat and Mass Transfer 171, 2021, 121082.
[7] Kitayamaa S., Tamada K., Numerical optimization of process parameters in plastic injection molding for minimizing weldlines and clamping force using conformal cooling channel, Journal of Manufacturing Processes 32, 2018, pp. 782-790.

[8] Kuo C.C., Xu W.C., Effects of different cooling channels on the cooling efficiency in the wax injection molding process, The International Journal of Advanced Manufacturing Technology 98, 2018, pp. 887-895. https://doi.org/10.1007/s00170-018-2345-7.

[9] Torres-Alba A., Manuel J., A New Conformal Cooling Design Procedure for Injection Molding Based on Temperature Clusters and Multidimensional Discrete Models, Polymers 2020, 12, 154. doi:10.3390/polym12010154.

[10] Venkatesh G., Ravi Kumar Y., Raghavendra G., Comparison of Straight Line to Conformal Cooling Channel in Injection Molding, 5th International Conference of Materials Processing and Characterization (ICMPC 2016), Venkatesh G. et al/Materials Today: Proceedings 4, 2017, pp. 1167-1173.

[11] Xu X., Sachs E., Allen S., Cima M., Designing conformal cooling channels for tooling, MIT Cambridge, MA 02139, 1998.

[12] Sachs E., Wylonis E., Allen S., Cima M., Guo H., Production of injection molding tooling with conformal cooling channels using the three dimensional printing process, Polymer Engineering and Science, volume 40, Issue 5, 2004, pp. 1232-1247.

[13] Sachs E., Allen S., Guo H., Banos J., Cima M., Serdy J., Brancazio D., Progress on Tooling by 3D Printing; Conformal Cooling, Dimensional Control, Surface Finish and Hardness, 1997, pp. 115-123. https://repositories.lib.utexas.edu/handle/2152/70331

[14] Ferreira J.C., Mateus A., Studies of rapid soft tooling with conformal cooling channels for plastic injection moulding (2003) Journal of Materials Processing Technology, volume 142, Issue 2, 2003, pp. 508-516.

[15] Meckley J., Edwards R., A Study on the Design and Effectiveness of Conformal Cooling Channels in Rapid Tooling Inserts, the Technology Interface Journal, ISSN\# 1523-9926, 2009. [16] Wang Y., Yu K.-M., Wang C.C.L., Zhang Y., Automatic design of conformal cooling circuits for rapid tooling, ComputerAided Design, volume 43, Issue 8, 2011, pp. 1001-1010.

[17] Au K.M., Yu K.M., Chiu W., Visibility-based conformal cooling channel generation for rapid tooling, Computer-Aided Design, Volume 43, Issue 4, 2011, pp. 356-373.

[18] Au K.M., Yu K.M., Variable distance adjustment for conformal cooling channel design in rapid tool, J. Manuf. Sci. Eng., 2014, 136 (4), pp. 1087-1357.

[19] Agazzi A., Sobotka V., Le Goff R., Uniform cooling and part warpage reduction in injection molding thanks to the design of an effective cooling system, Key Engineering Materials, 2013, pp. 554557:1611-1618.

[20] Mayer S., Optimised mould temperature control procedure using DMLS, EOS Whitepaper (optimizing mould temperature control for better products), EOS GmbH Electro Optical Systems, Robert-Stirling-Ring 1, D-82152 Krailling/Munich.

[21] Menges G., Michaeli W., Mohren P., How to Make Injection Molds. 3rd edn. Hanser Publishers, Munich, 2000), http://s2.iranmavad.com/book/en/how-to-make-injection-molds.pdf. 